\title{
Exacerbations of chronic obstructive pulmonary disease: It is time to rename
}

Mona Bafadhel' ${ }^{1}$, Philip Collis ${ }^{2}$, Gerard Criner ${ }^{3}$, Mark T. Dransfield ${ }^{4}$, Wim Janssens ${ }^{5}$, Vanessa M McDonald ${ }^{6}$, Claus F. Vogelmeier ${ }^{7}$, Richard EK Russell ${ }^{1}$

${ }^{1}$ Respiratory Medicine Unit, Nuffield Department of Clinical Medicine, University of Oxford, United Kingdom

${ }^{2}$ Patient living with COPD. United Kingdom

${ }^{3}$ Department of Thoracic Medicine and Surgery, Lewis Katz School of Medicine at Temple University, Philadelphia PA, USA

${ }^{4}$ Lung Health Center, University of Alabama at Birmingham, Birmingham, AL, USA

${ }^{5}$ Department of Respiratory Medicine, University Hospital Leuven, KULeuven, Belgium

${ }^{6}$ Priority Research Centre for Healthy Lungs, The University of Newcastle, NSW, Australia

${ }^{7}$ Department of Medicine, Pulmonary and Critical Care Medicine, University Medical Center Giessen and Marburg, Philipps-Universität Marburg, Germany, Member of the German Center for Lung Research (DZL)

Corresponding author: Dr Mona Bafadhel, mona.bafadhel@ndm.ox.ac.uk

Corresponding address: NDM Research Building, Old Road Campus, Oxford. OX3 7FZ. United Kingdom 


\section{COPD: The Crisis}

Words have meaning. In medicine, our terminology is transfixed, with repercussions in translation between languages, amongst healthcare professionals, and lay terms to patients. For example, in using COPD as an abbreviation, the letters C, O, P and D, in some languages do not exist, whilst in lay terms chronic obstructive pulmonary disease literally means a longterm lung problem. To overcome the non-specificity of using a catch-all term that fails to characterise the unique features of an individual patients' symptoms, we now try to determine phenotypes and treatable traits of COPD. Nonetheless, we have neglected translating the term exacerbation, an event that significantly impacts morbidity and mortality in patients with COPD. Defining the exacerbation event accurately will be a great advance; however, we believe that it is imperative to redefine the term and we propose that an exacerbation of COPD should be renamed a COPD crisis.

\section{Why do we need something new?}

The English dictionary defines the noun exacerbation to the 'process of making a problem, bad situation or negative feeling, worse'1. The term exacerbation is derived from the Latin verb exacerbare; completed from the Latin ex-and acerbus which translated mean expressing (ex-) and harsh or bitter (acerbus). At present as a noun, the term exacerbation is not specific, describing little of the 'processes that make a problem' and leads to misdiagnosis, misunderstanding and a lack of advancement in the field. It is not unusual to be in a clinic with a patient, trying to rephrase the question 'how many exacerbations have you had' several times. The majority of our patients do not know what the term exacerbation means with fewer than $2 \%$ of patients understanding the word ${ }^{2}$, and we often have to resort to trying different terms such as asking how many 'chest infections' 'flare-ups' or 'times have you taken steroids or antibiotics for your chest'. Furthermore, lessons from severe asthma ${ }^{3}$, demonstrate that patients view the term insulting as it trivialises their problem. If our patients do not understand us, then as healthcare practitioners we are failing in our attempts to help our patients.

\section{Why is Crisis applicable in COPD?}

The definition of crisis ${ }^{4}$ includes: 'a time of disagreement, confusion or suffering', 'an extremely difficult or dangerous point in a situation' and 'a moment during a serious illness when there is the possibility of suddenly getting either better or worse'. We have underlined the points that are particularly relevant to our patients with COPD. These acute episodes in the natural course of COPD, are associated with patient suffering ${ }^{5}$, are a crossroads in the disease course requiring management decisions ${ }^{6}$, and are associated with increased morbidity and mortality ${ }^{7}$. The word crisis comes from the Greek 'krisis' which was an important concept first described by Hippocrates. In antiquity, crisis was used to describe a turning point in the disease at which 
either the patient or the illness would prevail. Moreover, the crisis, described by Hippocrates, could be followed by a relapse. These relapses would occur on critical days usually at a fixed time-point after the first insult. This has already been described in our COPD patients ${ }^{8}$. Since the 1970's, the adoption of the term crisis has been paramount to Psychiatry. The mental health crisis relates to the occurrence of a "new situation in which the stresses associated with key values threaten to exceed the ability to cope with them', the severity of which refers to the person's reaction to the event. A COPD crisis would not be unfamiliar to both respiratory and non-respiratory clinicians. In Endocrinology, we are primed to look for the Addisonian or thyrotoxic crisis; in Cardiology or Neurology, we may be treating a hypertensive crisis; whilst in Haematology we fear the blast and the sickle cell crisis. In Psychiatry and Geratology, a crisis triggers an immediate response from the multi-disciplinary team. If we remove 'key values', from the mental health crisis definition and take into account the underlined points above, in defining the COPD crisis, then we have 'a point in a new situation in which the stresses threaten to exceed the ability to cope, where there is the possibility of suddenly getting either better or worse'. This is applicable to an inflammatory, cardiac or psychological insult that necessitate a medical review or additional treatment, taking into account the patient experience.

\section{What type of COPD crisis can you have?}

In the $19^{\text {th }}$ century, medical crises were ascribed to illness of an infectious nature. The turning point, that the patient or the illness could triumph, was especially relevant to the clinical situation of pneumonia pre-antibiotics. Temporally, several outcomes were described. The crisis, as the seminal event, could be followed by a lengthy period of recovery (protracted or prolonged crisis), several plateaus (interrupted or recurrent crisis) or a false crisis (pseudocrisis). In Respiratory Medicine, we are familiar with acute, sub-acute and resolving illness, which we could ascribe to the COPD crisis. Mild events that may not necessarily require a medical review could be a potential crisis, whilst those that we have termed moderate or severe in the past, are called COPD crisis, given the estimated need for intervention. Finally, delineating the heterogeneity of the COPD crisis would be part of redefining the term. The use of the term crisis as a diagnosis enables the clinician to refer to the temporal association as well as concluding with the factors that have led to the critical point. This is applicable to an inflammatory, cardiac, or psychological insult that necessitates medical review or additional treatment, which takes into account the patient experience. We suggest that in the renaming of the COPD crisis, there is an explicit requirement to associate temporally and to seek an underlying cause (table 1). We propose the following definition for a COPD crisis: a point in time in a new situation when identified stresses threaten to exceed the ability to cope and there is a possibility of suddenly getting better or worse. For example, a patient may experience a COPD crisis related to a virus, bacteria, cardiac event, or social isolation and anxiety. A diagnosis of a COPD crisis would refer to the temporal association and conclude with factors that have led to the critical point e.g. a rapid COPD crisis associated with Cor Pulmonale (see table 1). 


\begin{tabular}{|l|l|l|}
\hline COPD Crisis & Temporal association & Potential underlying cause (known/unknown) \\
\hline $\begin{array}{l}\text { potential, } \\
\text { confirmed }\end{array}$ & $\begin{array}{l}\text { rapid, sub-acute, protracted, } \\
\text { resolving }\end{array}$ & $\begin{array}{l}\text { virus, bacteria, cardiac dysfunction, anxiety, } \\
\text { social isolation }\end{array}$ \\
\hline
\end{tabular}

*not exhaustive list

\section{What will our patients think?}

Our patients worry about heart ${ }^{9}$ and brain attacks ${ }^{10}$. This confers an urgency, with the implication that assessment may be required. Whilst the frequent use of the word crisis in geopolitical and economic arenas may diminish its significance, it is important to reflect that in medicine its use has spanned Millenia. We thus propose to change to a term that is recognisable to healthcare practitioners and to patients. Asking our patients what their preferred terms are and what they think of COPD crisis will offer resolution. This is a unique opportunity where the COPD crisis will heighten our determination to improving the health of patients with COPD. 


\section{Source of funding:}

No funding sources to report

\section{Conflicts of interest statement:}

None of the authors report any conflicts of interest related to this submission. MB reports grants from AZ, personal fees from AZ, Chiesi, GSK, outside the submitted work. PC has nothing to disclose. GC reports grants from Boehringer- Ingelheim, grants from Novartis, grants from Astra Zeneca, grants from Respironics, grants from Medlmmune, grants from Actelion, grants from Forest, grants from Pearl, grants from Ikaria, grants from Aeris, grants from PneumRx, grants from Pulmonx, other from HGE Health Care Solutions, Inc, other from Amirall, other from Boehringer- Ingelheim, other from Holaira, outside the submitted work. MTD reports personal fees from Boehringher Ingelheim, personal fees from GlaxoSmithKline, other from Novartis, personal fees from AstraZeneca, other from Yungjin, personal fees and other from PneumRx/BTG, personal fees and other from Pulmonx, other from Boston Scientific, personal fees from Quark Pharmaceuticals, personal fees from Mereo, grants from American Lung Association, grants from $\mathrm{NIH}$, grants from Department of Veterans Affairs, outside the submitted work. WJ reports grants from Astra Zeneca and Chiesi, outside the submitted work; VMM reports grants and personal fees from AstraZeneca, grants and personal fees from GlaxoSmithKline, personal fees from Menarini, outside the submitted work; CFV reports grants and personal fees from AstraZeneca, grants and personal fees from Boehringer Ingelheim, grants and personal fees from Chiesi, grants and personal fees from GlaxoSmithKline, grants and personal fees from Grifols, grants and personal fees from Mundipharma, grants and personal fees from Novartis, personal fees from Cipla, personal fees from Berlin Chemie/Menarini, personal fees from CSL Behring, personal fees from Teva, grants from German Federal Ministry of Education and Research (BMBF) Competence Network Asthma and COPD (ASCONET), grants from Bayer Schering Pharma AG, grants from MSD, grants from Pfizer, personal fees from Nuvaira, outside the submitted work. REKR reports personal fees and non-financial support from Chiesi, personal fees from Boehringer Ingelheim, personal fees from Glaxosmithkline, outside the submitted work. All authors have read and approved the manuscript for submission and completed conflict of interest forms. 


\section{References}

1. "exacerbation nOO, Oxford University Press, June 2019, www.oed.com/view/Entry/65509. Accessed 21 August 2019.

2. Kessler R, Stahl E, Vogelmeier C, et al. Patient understanding, detection, and experience of COPD exacerbations: an observational, interview-based study. Chest 2006;130:133-42.

3. Jones KA, Gibson PG, Yorke J, Niven R, Smith A, McDonald VM. Attack, flare-up, or exacerbation? The terminology preferences of patients with severe asthma. J Asthma 2019:110.

4. "crisis nOO, Oxford University Press, June 2019, www.oed.com/view/Entry/44539. Accessed 11 October 2019.

5. Cappa V, Marcon A, Di Gennaro G, et al. Health-related quality of life varies in different respiratory disorders: a multi-case control population based study. BMC Pulm Med 2019;19:32.

6. From the Global Strategy for the Diagnosis, Management and Prevention of COPD, Global Initiative for Chronic Obstructive Lung Disease (GOLD) 2017. Available from: http://goldcopd.org.

7. Suissa S, Dell'Aniello S, Ernst P. Long-term natural history of chronic obstructive pulmonary disease: severe exacerbations and mortality. Thorax 2012;67:957-63.

8. Hurst JR, Donaldson GC, Quint JK, Goldring JJ, Baghai-Ravary R, Wedzicha JA. Temporal clustering of exacerbations in chronic obstructive pulmonary disease. Am J Respir Crit Care Med 2009;179:369-74.

9. Wiles R. Patients' perceptions of their heart attack and recovery: the influence of epidemiological "evidence" and personal experience. Social Science \& Medicine 1998;46:1477-86.

10. Hux K, Rogers T, Mongar K. Common Perceptions About Strokes. Journal of Community Health 2000;25:47-65. 